\title{
Effectiveness and Utilization Pattern of Cognitive Behavior Therapy of Anxiety Disorders: Evidence from a Psychiatry Clinic
}

\author{
Sudhir Hebbar
}

\begin{abstract}
Psychotherapy efficacy studies are conducted in highly controlled research settings. In contrast, effectiveness studies are done in routine clinical practice. In India, the literature on psychotherapy outcome is almost nonexistent.
\end{abstract}

Materials and methods: Here is a retrospective effectiveness study done by a psychiatrist in his clinic. A total of 67 patients visited for the treatment of anxiety disorders, whose data were available for analysis.

Results: Out of this sample, 44 patients opted for cognitive behavior therapy (CBT) of which 20 (45\%) patients dropped out of therapy by the $3 \mathrm{rd}$ session. Male patients represented 4 times more than female patients. The average number of sessions attended was 5.4. Of the 24 patients who attended 4 and more number of sessions, on Clinical global impression scale, 10 (41\%) improved very much, 11 (45\%) improved much, $2(8 \%)$ improved minimally, and 1 (4\%) did not change.

Conclusion: This indicates CBT is quite effective for anxiety disorders in patients who attend 4 and more sessions. Early dropout is a significant obstacle to the effectiveness.

Keywords: Anxiety disorders, Cognitive behavior therapy, Effectiveness, Efficacy, Psychotherapy.

How to cite this article: Hebbar S. Effectiveness and Utilization Pattern of Cognitive Behavior Therapy of Anxiety Disorders: Evidence from a Psychiatry Clinic. J Med Sci 2015;1(3):52-54.

\section{Source of support: Nil}

Conflict of interest: None

\section{INTRODUCTION}

The current trend in psychotherapy is to establish its effectiveness. ${ }^{1,2}$ Efficacy of psychotherapy has been well established by a series of older meta-analysis, ${ }^{3,4}$ and recently, efficacy of cognitive behavior therapy $(\mathrm{CBT})^{5,6}$ and psychodynamic psychotherapy ${ }^{7-9}$ was also established. The efficacy is comparable to that of medications and with added benefit of lesser recurrences. Why then

\section{Professor}

Department of Psychiatry, RajaRajeswari Medical College and Hospital, Bengaluru, Karnataka, India

Corresponding Author: Sudhir Hebbar, Professor, Department of Psychiatry, RajaRajeswari Medical College and Hospital Bengaluru, Karnataka, India, e-mail: drsudhirhebbar@gmail.com effectiveness of psychotherapy needs to be established separately? In contrast to pharmacotherapy, psychotherapy effectiveness varies markedly, conducted in highly controlled research settings and is done on cases excluding co-morbidities. In contrast, effectiveness studies are done in routine clinical practice where co-morbidities are not excluded. In India, the literature on psychotherapy outcome is almost nonexistent. In a review, ${ }^{10}$ Kuruvilla K has lamented about the tenuous relation between behavior therapy and Indian psychiatry. Modern-day CBT and psychotherapies have little resemblance to "behavior therapy" of bygone days. For anxiety disorders, CBT has the maximum evidence base. ${ }^{11}$ For depression and personality disorders, several psychotherapies, such as psychodynamic, emotion-focused therapy, and CBT (e.g., schema therapy, an extension of AT Beck's cognitive therapy) have demonstrated efficacy. Not surprisingly, all these therapies share similarities when it comes to the treatment of personality disorders and depression. ${ }^{12}$ As CBT has good evidence for anxiety disorders, the author conducted CBT espoused by Beck et al. ${ }^{13-15}$

\section{AIMS}

To study, the author conducted CBT espoused by Beck et al. ${ }^{13-15}$ and to study the utilization pattern, socioeconomic variables, and effectiveness of CBT for anxiety disorders in a psychiatry clinic.

\section{MATERIALS AND METHODS}

A total of 73 patients needed treatment for anxiety disorders at the author's clinic, in the 3-year-period between 2012 and 2014. Because of lack of proper data, 6 patients were excluded from the study. Out of the remaining 67 patients, 23 subjects opted for only medication. Forty four patients attended at least one CBT session of one-hour duration. These 44 patients were analyzed for utilization pattern and outcome of CBT. Patients were offered either or both of medications or CBT. Therapist's clinical diary was used as the source of information and the data were analyzed retrospectively. Clinical global impression scale was used to evaluate the outcome. ${ }^{16}$ Improvement was rated on the termination of therapy either by enquiry over phone or in the clinic. 


\section{RESULTS}

The number of patients who attended at least one CBT session was 44 . Table 1 shows the sociodemographic features and utilization pattern. A male preponderance of $82 \%$ was noted. Patient's mean age was 30.8 years. Most patients were graduates and came from middle or upper socioeconomic status. Almost all patients had visited a psychiatrist in the past. Eleven patients (25\%) had personality disorders, mostly avoidant and obsessive-compulsive and dependent types. Thirty-three patients (75\%) were on medications when they entered therapy. In this study, the mean duration of illness was 3.5 years. Inadequate response to medication was the important reason for choosing CBT. Out of these patients, 10 (23\%) stopped medications, 7 (16\%) reduced the medications, and the others maintained their medication, at the end of the therapy. Only 2 patients required to increase their medications. In our study, the mean number of sessions attended was 5.4. A total of $45.5 \%$ of patients terminated therapy in the first 3 sessions. Diagnosis for which psychotherapy done was panic disorder with or without agoraphobia 17 (38\%), obsessive compulsive disorder 11 (25\%), social phobia $9(20 \%)$, and generalized anxiety disorder 7 (16\%). The improvement after CBT is shown in Table 2. In the full sample of 67 patients (including patients who rejected CBT), 10 (15\%) patients improved a lot, 17 (25\%) patients improved marginally, 7 (10\%) improved minimally, and $33(49 \%)$ patients did not improve. Out of 44 patients who attended at least one session, 10 (22.7\%) improved very much, 17 (38.6\%) improved much, 7 (15.9\%) improved minimally, and $10(22.7 \%)$ did not change. Out of 24 patients who attended 4 and more number of sessions, 10 (41\%) improved very much, 11 (45\%) improved much, 2 (8\%) improved minimally, and 1 (4\%) did not change.

\section{DISCUSSION}

A male preponderance noted in this study may be a cultural artifact. Western studies do not report this pattern. One recent study from India shows threefold preponderance of male patients. ${ }^{17}$ The mean number of attended sessions is consistent with the literature. Garfield SL in 1978 reported that patients attend a mean number of 5 to 6 sessions. ${ }^{18}$ One classic study ${ }^{19}$ observed that about $60 \%$ of improvement in psychotherapy occurs in the first 7 visits, $70 \%$ by 6 months, and $80 \%$ by 1 year. This pattern conforms
Table 1: Sociodemographic variables and utilization pattern

\begin{tabular}{ll}
\hline Variable & $n(\%)$ \\
\hline Gender & \\
Male & $36(82)$ \\
Female & $8(18)$ \\
Mean age in years & 30.8 \\
Education & \\
Post graduation & $6(13)$ \\
Graduation & $34(77)$ \\
Under graduation & $4(10)$ \\
Mean number of sessions & 5.4 \\
Mean duration of illness in years & 3.5 \\
Patients who were on medications & $33(75)$ \\
Patients who stop medications & $10(23)$ \\
Patients with personality disorder & $11(25)$ \\
Early drop out (3 \& less sessions) & $20(45.5)$ \\
\hline
\end{tabular}

to the law of diminishing returns. This early improvement is a well-observed phenomena and seen in the current study also. Dropout in psychotherapy is defined in various ways. Majority of dropouts happen in the early part of therapy, that too within a few sessions. The dropout rate was $45 \%$ in the first 3 visits seen in this study, which is similar to that noted in the psychotherapy literature. The other way of reporting dropout is failure to complete a preset number of sessions. Such studies ${ }^{20-22}$ have reported dropout in the range of 19 to $47 \%$. One study from India ${ }^{17}$ on CBT of panic disorder noted a dropout of $30 \%$. In the current study, such a condition of fixed number of sessions was not used. Among patients who attended 4 and more CBT sessions, 10 patients improved much. Since no patient improved to "much improved" level among early dropouts, the number needed to treat (NNT) to get this effect in this sample is 2.4. This NNT is approximately equal to Cohen's d of 0.8 , which indicates a large effect size. If intent to treat sample (44 patients) is considered, this comes to a NNT of 4.4. This corresponds to moderate effect size. It should be noted that these results do not include moderately improved patients. In fact, 11 (45\%) patients improved to a moderate extent in the core sample who attended 4 and more sessions. This improvement is unlikely due to the use of medications as many patients either stopped or reduced medications. Interestingly, these results are quite close to a meta-analysis of panic disorder studies. ${ }^{23}$ Authors in that meta-analysis have quoted " $63 \%$ of patients who completed the study were benefitted, in the intention to treat sample $34 \%$ of patients got improved and when the

Table 2: Improvement pattern

\begin{tabular}{|c|c|c|c|c|c|}
\hline Patients & Numbern (\%) & $\begin{array}{l}\text { Very much } \\
\text { improved } n(\%)\end{array}$ & $\begin{array}{l}\text { Much improved } \\
n(\%)\end{array}$ & $\begin{array}{l}\text { Minimally } \\
\text { improved n (\%) }\end{array}$ & $\begin{array}{l}\text { No change } \\
n(\%)\end{array}$ \\
\hline Full Sample & $67(100)$ & $10(15)$ & $17(25)$ & $7(10)$ & $33(49)$ \\
\hline Intent to treat sample & $44(65)$ & $10(22.7)$ & $17(38.6)$ & $7(15.9)$ & $10(22.7)$ \\
\hline Patients with 4 and more sessions & $24(36)$ & $10(41)$ & $11(45)$ & $2(8)$ & $1(4)$ \\
\hline
\end{tabular}


excluded patients were also taken into account, only 19\% of them improved". The limitations of this study include that the retrospective open design and the improvement measured was global. However, it has the merit of being done in a paid clinic and by a self-trained psychotherapist without having any bias toward medications or therapy. This study implies that CBT can be disseminated eminently. This study shows the magnitude of non-acceptance of CBT and also dropout rates. Co-morbidities are not excluded in this study.

\section{CONCLUSION}

Cognitive behavior therapy is quite effective for anxiety disorders in patients who attend 4 and more sessions. Minimization of early dropout can boost the effectiveness further.

Psychotherapy of anxiety disorders for adult outpatients is effective in every day clinical practice.

\section{REFERENCES}

1. Seligman M. The effectiveness of psychotherapy: the consumer reports study. Am Psychol 1995 Dec;50(12):965-974.

2. Hunsley J, Elliot K, Therrien Z. The efficacy and effectiveness of psychological treatments. Canada: Canadian Psychological Association; 2013.

3. Smith ML, Glass GV. Meta analysis of psychotherapy outcome studies. Am Psychol 1977 Sep;32(9):752-760.

4. Lepsy MW, Wilson DB. The efficacy of psychological, educational and behavioral treatments: confirmation. Am Psychol 1993 Dec;48(12):1181-1209.

5. Butler AC, Chapman JE, Forman EM, Beck AT. The empirical status of cognitive-behavior therapy: a review of meta-analysis. Clin Psychol Rev 2006 Jan;26(1):17-31.

6. Hofmann SG, Asnaani A, Vonk IJJ, Sawyer AT, Fang A. The efficacy of cognitive-behavior therapy: a review of meta-analysis. Cognit Ther Res 2012 Oct;36(5):427-440.

7. Leichsenring F, Rabung S, Leibing E. The efficacy of short term psychodynamic psychotherapy in specific psychiatric disorders: a meta-analysis. Arch Gen Psychiatry 2004 Dec;61(12):1208-1216.

8. Leichsenring F, Rabung S. Long-term psychodynamic psychotherapy in complex mental disorders: update of a meta-analysis. Br J Psychiatry 2011 Jul;199(1):15-22.
9. Shedler J. The efficacy of psychodynamic psychotherapy. Am Psychol 2010 Feb-Mar;65(2):98-109.

10. Kuruvilla K. Indian contributions to behavior therapy. Indian J Psychiatry 2010 Jan;52 (Suppl 1):S371-377.

11. Chambless DL, Baker MJ, Baucom DH, Beutler LE, Calhoun KS, Crits-Christoph P. Update on empirically validated therapies - 2. Clin Psychol 1998;51:1-16.

12. Clarkin JF, Fonagy P, Gabbard GO. Psychodynamic psychotherapy for personality disorders: a clinical hand book. Washington (DC): American Psychiatry Publishing; 2010. p. 19.

13. Beck AT. Cognitive therapy and emotional disorders. New York (NY): International Universities Press; 1976.

14. Beck AT, Emery G. (with Greenberg RL). Anxiety disorders and phobias: a cognitive perspective. Revised paperback ed. New York (NY): Basic Books; 2005.

15. Clark DA, Beck AT. Cognitive therapy of anxiety disorders: Science and practice. New York (NY): Guilford Press; 2010.

16. Guy, W. The clinical global impression scale. In: ECDEU assessment manual for psychopharmacology-revised. Rockville (MD): US Department of Health, Education and Welfare, ADAMHA, MIMH Psychopharmacology Research Branch; 1976. pp 218-222.

17. Manjula M, Kumariah V, Prasadarao P, Raguram R. Cognitive behavior therapy in the treatment of panic disorder. Ind J Psychiatry 2009 Apr;51(2):108-116.

18. Garfield SL. Research on client variables in psychotherapy. In: Garfield SL, Bergin AE, editors. Handbook of psychotherapy and behavior change: an empirical analysis. 2nd ed. New York (NY): Wiley; 1978. p. 59.

19. Howard KI, Kopte SM, Krause MS, Orlinsky DE. The doseeffect relationship in psychotherapy. Am Psychol 1986 Feb;41(2):159-164.

20. Bados A, Balaguer G, Saldaña C. The efficacy of cognitive behavior therapy and the problem of drop-out. J Clin Psychol 2007 Jun;63(6):585-592.

21. Swift JK, Greenberg RP. Premature discontinuation in adult psychotherapy: a meta-analysis. J Consult Clin Psychol 2012 Aug;80(4):547-559.

22. Wierzbicki M, Pekarik G. A meta-analysis of psychotherapy dropout. Prof Psychol: Res and Prac 1993;24(2): 190-195.

23. Westen D, Morrison K. A multidimensional meta-analysis of treatments for depression, panic and generalized anxiety disorder: an empirical examination of the status of empirically supported therapies. J Consult Clin Psychol 2001 Dec;69(6): 875-899. 